NELSON, Rocco Antonio Rangel Rosso. ROCHA, Joyce Michelle de Melo. Do princípio da tripartição dos poderes: um estudo dogmático em relação as agências reguladoras. Revista Eletrônica Direito e Política, Programa de Pós-Graduação Stricto Sensu em Ciência Jurídica da UNIVALI, Itajaí, v.11, n.1, $1^{\circ}$ quadrimestre de 2016. Disponível em: www.univali.br/direitoepolitica - ISSN 1980-7791.

\title{
DO PRINCÍPIO DA TRIPARTIÇÃO DOS PODERES: UM ESTUDO DOGMÁTICO EM RELAÇÃO AS AGÊNCIAS REGULADORAS
}

\author{
THE PRINCIPLE OF SEPARATE POWERS: A DOGMATIC STUDY \\ REGARDING THE REGULATORY AGENCIES
}

Rocco Antonio Rangel Rosso Nelson ${ }^{1}$

Joyce Michelle de Melo Rocha ${ }^{2}$

SUMÁRIO: Introdução; 1 . Do princípio da tripartição dos poderes; 2. Necessidade de mitigação da teoria da tripartição dos poderes; 3. Escopo histórico das agências reguladoras; 4. As agências reguladoras e sua adequação ao princípio da separação dos poderes; Considerações finais; Referências

\section{RESUMO}

O artigo procura colher posicionamentos para defender a legitimidade da atuação das agências reguladoras, atendendo aos preceitos da Constituição Federal de 88. Verifica-se a importância de tomadas de decisões dentro dos aspectos da especificidade técnica e, principalmente, dentro de um tempo razoável, avocando, dessa forma, o princípio da eficiência que deve permear a Administração Pública, e que se encontra encartado na Carta Magna de 88, como um dos pilares da atividade pública. A natureza constitucional de certas garantias não é afastada e nem se presume uma

1 Graduado em direito pela Universidade Potiguar (2004). Especializou-se em Ministério Público, Direito e Cidadania pela Fundação Escola Superior do Ministério Público do Rio Grande do Norte (2007), bem como na área de Direito Penal e Criminologia pela Universidade Potiguar (2007). Mestre em Direito Constitucional pela Universidade Federal do Rio Grande do Norte (2009). Foi professor da Faculdade de Ciências Cultura e Extensão do Rio Grande do Norte - FACEX, por um período de 5 anos, tendo lecionados as cátedras de Direito Penal - I, Direito Penal II, Direito Penal III, Direito Penal IV, Direito Processual Penal I e Direito Processual Penal - II, Direito Processual Constitucional, Direito Tributário, Direito Empresarial, Direito Administrativo, Direito da Seguridade Social. Lecionou nas pósgraduações \&quot; lato sensu\&quot; em MBA em Gestão Pública, MBA em Gestão Financeira, MBA em Auditoria e Perícia Contábil, em Elaboração e Gerenciamento de Projetos e em Assistência Sócio-jurídica e Segurança Pública. Já ministrou aulas na faculdade Estácio de Sá e na Universidade Federal do Rio Grande do Norte - UFRN. Atualmente, professor efetivo de Direito, no Instituto Federal do Rio Grande do Norte - IFRN, articulista e poeta. E-mail: rocconelson@hotmail.com.

${ }^{2}$ Graduado pela Universidade Federal Rural do Semiárido (2002). Tem experiência na área de Agronomia. E-mail: joycemmr@hotmail.com. 
usurpação nos poderes legislativos e jurisdicionais pelas agências reguladoras. A atividade das agências reguladoras visa atender ao que foge da alçada dos poderes legislativos e judiciais, como um preenchimento de lacuna de cunho administrativo, respaldadas pelos ditames constitucionais. A pesquisa em tela, fazendo uso de uma metodologia de análise qualitativa, usando-se os métodos de abordagem hipotético-dedutivos de caráter descritivo e analítico, preponderando o tipo jurídico-compreensivo, tem por linha de fundo o estudo das agências reguladoras e sua adequação aos ditames normativos do dogma do princípio da tripartição dos poderes.

Palavras-chave: Administração Pública; Agências reguladoras; Conflito; Tripartição dos poderes; Legitimidade;

\section{ABSTRACT}

The article tries to scoop placements defend the legitimacy of the actions of regulatory agencies, given the precepts of the Constitution of 88 . There is the importance of making decisions within the technical aspects of specificity and, especially, within a reasonable time, climbing thus the principle of efficiency that should permeate the Government, and which is chartered in the Constitution of 88 , as one of the pillars of public activity. The nature of certain constitutional guarantees is remote and not presumed an encroachment on the legislative and judicial powers by regulatory agencies. The activity aims to meet the regulatory agencies that escapes the purview of the legislative and judicial powers, as a gap fill of the administration, backed by constitutional dictates. The search screen, using a qualitative analysis methodology, using the methods of hypotheticaldeductive approach to descriptive and analytical character was more prevalent the legal and understanding type, is the bottom line the study of regulatory agencies and their suitability the normative dictates of the dogma of the principle of separate powers.

Keywords: Public administration; Regulatory agencies; Conflict; Separate powers; Legitimac;

\section{INTRODUÇÃO}

Conceituar o que seja uma agência reguladora, em função da sua heterogeneidade, nos dias de hoje é impossível, mas pode-se afirmar que a mesma se manifesta no mundo jurídico sob a forma de autarquia em regime especial, dotado de grande especialidade técnica, atuando em um setor específico ou geral da economia, com um alto grau de autonomia perante o Poder Executivo e amplo poder normativo (prerrogativa que vem gerando inúmeras controvérsias no ordenamento jurídico e ponto de discussão nessa dissertação), além da atribuição para a resolução dos conflitos entre empresas e usuários. ${ }^{3}$

\footnotetext{
3 "Agência reguladora independente seria uma autarquia especial, criada por lei para intervenção estatal no domínio econômico, dotada de competência para regulação de setor
} 
É em função dessas características referenciadas, retro, que começa a discussão sobre a constitucionalidade desta entidade administrativa, na qual, alguns autores ${ }^{4}$ afirmam categoricamente, que a mesma, está usurpando as funções do Poder Legislativo, do Judiciário e do Executivo, violando assim, o princípio da tripartição dos poderes previsto no art. $2^{\circ}$ da Carta Magna brasileira. ${ }^{5}$

Fazendo uso de uma metodologia de análise qualitativa, usando-se os métodos de abordagem hipotético-dedutivos de caráter descritivo e analítico, preponderando o tipo jurídico-compreensivo, tem por linha de fundo o estudo das agências reguladoras e sua adequação aos ditames normativos do dogma do princípio da tripartição dos poderes.

Ao analisar a questão a despeito do ferimento do princípio da tripartição dos poderes pelas agências reguladoras, traz-se à baila a essência da concepção kantiana, no que se refere à ideia de que o Estado não tem fins próprios, e que os mesmos devem coincidir com aqueles dos indivíduos da sociedade.

É a concepção moderna de que o essencial é o aspecto legal, devendo, para isso, que o poder seja tripartite.

Desde seus primórdios, os institutos administrativos veem sofrendo revisões pelo judiciário, no que concerne a seus excessos e deficiências.

Verificando-se os rudimentos de um direito administrativo inglês, percebeuse que novas soluções judiciárias eram necessárias para as novas exigências que surgiam. Adotou-se, então, o writ of certiorari para controlar atos praticados pelos órgãos administrativos coletivos, com fulcro no abuso de competências, já no século XVII. A common law responsabilizava aqueles que promovessem atos irregulares.

específico, inclusive com poderes de natureza regulamentar e para arbitramento de conflitos entre particulares, e sujeita a regime jurídico que assegure sua autonomia em face da Administração direta". (JUSTEN FILHO, Marçal. O direito das agências reguladoras independentes. São Paulo: Dialéctica, 2002, p. 344).

${ }^{4}$ Cf. RÁO, Vicente. 0 direito e a vida dos direitos. 60 ed. São Paulo: RT, 2005, p. 344. BUCCI, Maria Paula Dallari. Direito administrativo e políticas públicas. São Paulo: Saraiva, 2002, p. 29-30. DI PIETRO, Maria Sylvia Zanella. Direito Administrativo. $21^{\circ}$ ed. São Paulo: Atlas, 2007, p. 447. MELLO, Celso Antônio Bandeira de. "Poder" regulamentar ante o princípio da legalidade. Revista Trimestral de Direito Público. São Paulo: n. 7278, Malheiros, 1993, p. 73.

5 Art. 20 São Poderes da União, independentes e harmônicos entre si, o Legislativo, o Executivo e o Judiciário. 
Uma das grandes discussões acerca das agências reguladoras se configura no âmbito de alcance de seus poderes, principalmente sobre aspectos normativos.

A tripartição dos poderes é abstrata e se comunica simultânea e harmonicamente, com momentos em que um faz o papel do outro sem que seja ferido o campo de atuação desse outro.

Carlos Ari Sundfeld reconhece que na modernidade atual deixa de ser suficiente as normas abstratas e gerais produzidas pelo Poder Legislativo, advindo a necessidade de "normas mais diretas para tratar das especificidades, realizar o planejamento dos setores, viabilizar a intervenção do Estado em garantia do cumprimento ou a realização daqueles valores $(\ldots)^{\prime \prime} \cdot 6$

Numa análise dentro da perspectiva do direito positivo, Alexandre dos Santos Aragão identifica que o princípio da separação dos poderes nunca fora inserido em sua inteireza nos ordenamentos jurídicos e na prática os Estados burgueses ainda se distanciaram e muito dos seus postulados. ${ }^{7}$

Há receios no que se refere à inovação, como aqui verificado por Joaquín Tornos Mas, respaldado na obra de Alexandre Aragão, ${ }^{8}$ ao defender que "(...) a introdução na linguagem jurídica do conceito de regulação é problemática. A utilização de um novo termo dotado de diversos conteúdos choca-se com a necessária segurança que deve reger o mundo do Direito". Segurança que se levada em sua forma literal, afastará toda e qualquer forma de mudança necessária para acompanhar a dinâmica do mundo econômico.

Moncada é taxativo e afirma que "Da imperfeição da lei resulta que ela não pode prever tudo". ${ }^{9}$ Nesse sentido, permite-se a possibilidade de que novos

\footnotetext{
6 SUNDFELD, Carlos Ari (Coordenador). Direito administrativo econômico. São Paulo: Malheiros, 2006, p. 27.

7 SUNDFELD, Carlos Ari (Coordenador). Direito administrativo econômico. São Paulo: Malheiros, 2006, p.47.

8 ARAGÃO, Alexandre Santos de. Agências reguladoras e a evolução do direito administrativo econômico. Rio de Janeiro: Forense, 2006, p. 22.
}

${ }^{9}$ MONCADA, Luís S. Cabral de. Ensaio sobre a lei. Coimbra: Coimbra Editora, 2002, p. 15. 
institutos jurídicos possam atender aquelas situações até então não definidas pela lei. E é exatamente aí que entram as agências reguladoras.

A lacuna para solucionar problemas de ordem técnicas não pode ser suprida pelo legislativo ou por meios jurídicos se estes não dispõem de arcabouço de cunho técnico e específico, de modo a resolver conflitos com economicidade de tempo e, sendo assim, com eficiência.

O conceito de eficiência pode ser definido, nas palavras de Costodio Filho, através de dois sentidos, por ser esta tida como uma palavra ambígua:

[...] optando-se pelo sentido comum, o princípio da eficiência significaria ao agente administrativo a obrigação de satisfazer as necessidades dos cidadãos (consecução dos fins), com presteza e da maneira menos dispendiosa possível para a Administração (otimização dos meios). Aqui, eficiente seria a Administração que obtivesse os resultados que dela se esperam, pelo menor custo e no melhor tempo. Por outro lado, preferindo-se o sentido científico, o princípio da eficiência imporia ao agente administrativo somente o dever de se preocupar com o ótimo cumprimento de metas. Nessa hipótese, Administração eficiente seria aquela que utilizasse os recursos disponíveis racionalmente, com economicidade, mas descomprometida com a questão de metas e resultados, pois metas e resultados não se incluem na acepção científica de eficiência. ${ }^{10}$

A Emenda Constitucional no 19/98, que trata de importantes modificações na seara administrativa, segundo Lehfeld, parece ter adotado o sentido comum do qual não se extrai a distinção entre a eficiência, aferição dos meios e procedimentos, da eficácia, avalição dos resultados. ${ }^{11}$

Inserindo-se o aspecto constitucional, os princípios que blindam todas as ações da Administração Pública, devem ser obrigatoriamente observados, por serem tidos como norma constitucional, e assim sendo, de aplicação imediata e eficácia plena.

\footnotetext{
${ }^{10}$ COSTODIO FILHO, Ubirajara. A Emenda Constitucional 19/98 e o Princípio da Eficiência na Administração Pública. In : Cadernos de Direito Constitucional e Ciência Política, São Paulo: RT, n. 27, p. 210-217, abr./jul. 1999, p.212.

${ }^{11}$ Cf. LEHFELD, Lucas de Souza. Controle das agências reguladoras. São Paulo: Atlas, 2008, p.211-212.
} 
Isso significa que, todas as medidas sejam respaldadas por tais princípios, mesmo em detrimento dos dogmas estabelecidos para o que venha a se chamar coisa pública. Aqui se coaduna com perfeição os dizeres de Gomes Canotilho:

Este princípio, também designado por princípio da
eficiência ou princípio da interpretação efectiva, pode
ser formulado da seguinte maneira: a uma norma
constitucional deve ser atribuído o sentido que maior
eficácia Ihe dê. É um princípio operativo em relação a
todas e quaisquer normas constitucionais, e embora a
sua origem esteja ligada à tese da actualidade das
normas programáticas (Thoma), é hoje, sobretudo,
invocado no âmbito dos direitos fundamentais (no caso
de dúvidas deve preferir-se a interpretação que
reconheça maior eficácia aos direitos fundamentais). ${ }^{12}$

A teoria da tripartição dos poderes nasce com o intuito de reter o poder absolutista. ${ }^{13}$ E cumpriu essa necessidade, naquele momento.

O impasse é revelado sobre o fato de que as agências reguladoras parecerem extrapolar o seu campo de atuação, pela elaboração de normas que, à primeira vista, presumem perpassar as prerrogativas do Poder Legislativo. Sob essa ótica, também parece incitar o princípio da tripartição dos poderes. Configura-se, então, a temática a ser abordada nesse trabalho.

No desenvolver do objeto problema do presente ensaio se iniciará apresentando o contexto histórico do surgimento do princípio da tripartição dos poderes para em seguida adentrar nas razões na sua necessária mitigação, finalizando com a análise da forma de adequação desse verdadeiro axioma do constitucionalismo moderno com a figura das agências reguladoras.

12 CANOTILHO, José Joaquim Gomes. Direito Constitucional. 70 ed. Coimbra: Almedina, 2003, p. 1224.

13 "A separação e interdependência não é um esquema constitucional rígido mas apenas um princípio organizatório fundamental. Como tal, não há que perguntar pela sua realização estrita nem há que considerá-lo como um dogma de valor intemporal. Devemos perspectiválo como princípio histórico (K. Hesse) «em contacto» com uma ordem constitucional concreta. Como princípio constitucional concreto, o princípio da separação articula-se e combina-se com outros princípios constitucionais positivos (princípio de governo semipresidencialista ou de regime misto parlamentar-presidencial, princípio da conformidade dos actos estaduais com a Constituição, princípio da participação)". (Cf. CANOTILHO, José Joaquim Gomes. Direito Constitucional. 70 ed. Coimbra: Almedina, 2003, ps. 556-557). 


\section{DO PRINCÍPIO DA TRIPARTIÇÃO DOS PODERES}

Torna-se imprescindível a linha de pensamento de Nelson Saldanha quando se refere à mudança de concepções que promovem o desencadear de uma nova estrutura no ordenamento político, de modo que estas se amoldam e evoluem com os acontecimentos sociais e preconiza que

O advento de um Estado que, sem perder os caracteres já dados pelo absolutismo ao "Estado moderno" reforçou em sua estrutura o lado jurídico, adotando com forma jurídica imposta através de uma lei fundamental formada de limitações e garantias, pôs as condições para a eclosão de um novo pensamento constitucional. ${ }^{14}$

Inicia-se um incremento dos princípios no ordenamento jurídico, com a finalidade de resguardar os direitos sacralizados e inerentes a dignidade da pessoa humana. ${ }^{15}$

Inserindo neste contexto o princípio da tripartição dos poderes, tem-se o mesmo como componente basilar da Constituição juntamente com a ideia de garantias de direitos, segundo informa Nelson Saldanha. ${ }^{16}$

Os primeiros passos do princípio da tripartição dos poderes estão intrinsecamente ligados aos principais acontecimentos envolvendo as ideias liberais, e está caracterizado nas palavras de Paulo Bonavides ${ }^{17}$ "Estado constitucional da separação de poderes aquele que surgiu imediatamente após as duas grandes revoluções da segunda metade do século XVIII: a Revolução da Independência Americana e a Revolução Francesa".

14 SALDANHA, Nelson. Formação da Teoria Constitucional. Rio de Janeiro: Renovar, 2000, p. 03.

15 "Uma série de princípios, dentro da tendência especulativa que dominou o setecentos, ocupou desde então o mundo jurídico, a começar do significativo "princípio da legalidade", bastante ligado à justiça penal por causa inclusive da influência de Beccaria, mas em verdade presente em todos os ramos dos ordenamentos. (SALDANHA, Nelson. Formação da Teoria Constitucional. Rio de Janeiro: Renovar, 2000, p. 23).

16 SALDANHA, Nelson. Formação da Teoria Constitucional. Rio de Janeiro: Renovar, 2000, p.76.

17 BONAVIDES, Paulo. Teoria do Estado. São Paulo: Malheiros, 2007, p. 41. 
O pensamento do autor se desenvolve partindo da perspectiva de que

A filosofia política, expendida em livros do quilate do Contrato Social de Rousseau ou do Espírito das Leis de Montesquieu, teve na época sentido subversivo, porquanto, inspirando a ação revolucionária, traçou a linha-mestra das mutações profundas da sociedade. Foi, sobretudo, o breviário do novo credo, a cartilha por onde rezaram os constituintes de 1791 e 1793, depois de escreverem, iluminados das lições de tão sábios preceptores, a célebre Declaração dos Direitos do Homem. ${ }^{18}$

E declara que

Ali, em o no 16 do texto imortal, o gênio dos teoristas
da liberdade elaborou a fórmula da divisão de Poderes,
decretando em todas as Constituições que a
consagravam o termo dos regimes absolutos de
competências ilimitadas. ${ }^{19}$

Nasce, assim, o princípio que será alvo de muitas controvérsias desde a sua real efetividade como desencadeador de uma separação perfeitamente delineada de poderes do Estado (executivo, legislativo e judiciário) ou separação de funções dentro de tais poderes.

Dalmo de Abreu Dallari expôs a discussão acerca da polêmica sobre os liames entre poder e função do Estado. O autor enriquece o tema e dispõe:

Embora seja clássica a expressão separação de poderes, que alguns autores desvirtuaram para divisão de poderes, é ponto pacífico que o poder do Estado é uno e indivisível. É normal que haja muitos órgãos exercendo o poder soberano do Estado, mas a unidade do poder não se quebra por tal circunstância. Outro aspecto a considerar é que existe uma relação muito estreita entre as ideias de poder e de função do Estado, havendo mesmo quem sustente que é totalmente inadequado falar-se numa separação de poderes, quando o que existe de fato é apenas uma distribuição de funções. Assim, por exemplo, LEROY-BEAULIEU adota esta última posição, indo até mais longe,

18 BONAVIDES, Paulo. Teoria do Estado. São Paulo: Malheiros, 2007, p. 42.

19 BONAVIDES, Paulo. Teoria do Estado. São Paulo: Malheiros, 2007, p. 42. 
procurando demonstrar que as diferentes funções do Estado, atribuídas a diferentes órgãos, resultaram do princípio da divisão do trabalho. Diz ele que foi esse princípio, inconscientemente aplicado, que fez passarem ao Estado certas funções que a sociedade exercia instintivamente e que o Estado organiza com reflexão. ${ }^{20}$

A liberdade pautou o pensamento de Montesquieu ${ }^{21}$ em sua reflexão no que concerne a tripartição dos poderes. Este aspecto foi observado por Eros Grau que aduz que "A 'separação dos poderes' é, em Montesquieu, ${ }^{22}$ um mecanismo imediatamente voltado à promoção da liberdade do indivíduo;". ${ }^{23}$ Afirma ainda que:

O que importa verificar, inicialmente, na construção de Montesquieu, é o fato de que não cogita de uma efetiva separação de poderes, mas sim de uma distinção entre eles, que, não obstante, devem atuar em cima de equilíbrio. Isso fica bastante nítido na análise de outro trecho de sua obra: "Eis, assim, a constituição fundamental do governo de que falamos. O corpo legislativo sendo composto de duas partes, uma paralisará a outra por sua mútua faculdade de impedir. Todas as duas serão paralisadas pelo Poder Executivo,

\footnotetext{
20 DALLARI, Dalmo, de Abreu. Elementos de teoria geral do Estado. São Paulo: Saraiva, 2011, p. 214-215.

21 "É verdade que nas democracias o povo parece fazer o que quer; mas a liberdade política não consiste em se fazer o que se quer. Em um Estado, isto é, numa sociedade onde existem leis, a liberdade só pode consistir em poder fazer o que se deve querer e em não ser forçado a fazer o que não se tem o direito de querer. (...) Deve-se ter em mente o que é a independência e o que é a liberdade. A liberdade é o direito de fazer tudo o que as leis permitem; e se um cidadão pudesse fazer o que elas proíbem ele já não teria liberdade, porque os outros também teriam este poder". (MONTESQUIEU, Charles Louis de Secondat. O espírito das leis. Tradução de Antonio Lázaro de Almeida Prado. IN: Coleção "Os pensadores". São Paulo: Nova Cultural, 1996, p. 74).
}

22 "O princípio da separação de poderes, de tanta influência sobre o moderno Estado de direito, embora tenha tido sua sistematização na obra de Montesquieu, que o empregou claramente como técnica de salvaguarda da liberdade, conheceu todavia precursores, já na Antiguidade, já na Idade Média e tempos modernos. (...) Distinguira Aristóteles a assembléia-geral, o corpo de magistrados; e o corpo judiciário; ...". (BONAVIDES, Paulo. Ciência política. $14^{\circ}$ ed. São Paulo: Editora Malheiros, 2007, p. 146). "Toda Cidade tem três elementos, cabendo ao bom legislador examinar o que é mais conveniente para cada constituição. Quando essas partes forem bem ordenadas, a constituição será bem ordenada, e conforme diferem umas das outras, as constituições também diferem. A primeira dessas partes concerne à deliberação sobre assuntos públicos; a segunda, às magistraturas: qual deve ser instituída, qual deve ter sua autoridade específica e como os magistrados devem ser escolhidos; por último, relaciona-se a como deve \&poder judiciário". (ARISTÓTELES. Política. Tradução de Pedro Constantin. $5^{\circ}$ ed. São Paulo: Martin Claret, 2008, p. 170).

23 GRAU, Eros Roberto. O direito posto e o direito pressuposto. São Paulo: Malheiros, 2005, p. 226. 
que o será, por sua vez, pelo Poder Legislativo. Estes três poderes deveriam formar uma pausa ou uma inação. Mas como, pelo movimento necessário das coisas, eles são obrigados a caminhar, serão forçados a caminhar de acordo" (1973/161). ${ }^{24}$

Destarte, numa visão ampla, se deduz que nem mesmo aquele tido como o mais famoso pensador da teoria da separação dos poderes almejou afastar a convivência harmônica dos poderes do Estado.

\section{NECESSIDADE DE MITIGAÇÃO DA TEORIA DA TRIPARTIÇÃO DOS PODERES}

A teoria da tripartição dos poderes foi um dos elementos chaves do Estado Liberal. A questão que nos apresenta, hoje, é saber como o presente princípio, elegido a condição de pressuposto de existência de uma Constituição, segundo a Declaração dos Direitos do Homem, se redimensiona na estrutura estatal presente.

Vale ressaltar, de antemão, que não se questiona a importância do presente princípio, pois isso é inegável, sendo descoberto em seu tempo (séc. XVIII) como forma de protesto ideológico do liberalismo político contra o absolutismo monárquico ${ }^{25}$. Sem dúvida a teoria da tripartição dos poderes foi uma das alavancas da liberdade contemporânea, o paradigma das Constituições contra os arbítrios estatais, sendo um marco para o constitucionalismo democrático. ${ }^{26}$

Entretanto, a obediência a esse princípio em tela, segundo os moldes a qual foi constituído, nos dias atuais, constitui uma verdadeira contradição na

${ }^{24}$ GRAU, Eros Roberto. O direito posto e o direito pressuposto. São Paulo: Malheiros, 2005, p. 230.

${ }^{25}$ Cf. ARAGÃO, Alexandre Santos de. Legalidade e regulamentos no direito contemporâneo. Uma análise doutrinária e jurisprudencial. Revista de Direito Constitucional e Internacional. São Paulo: n. 41, p. 284-310, ed. RT, outubro-dezembro-2002, p. 287.

26 "A separação foi historicamente necessária quando o poder pendia entre governantes que buscavam recobrar suas prerrogativas absolutas e pessoais e o povo que, representado nos parlamentos, intentava dilatar sua esfera de mando e participação na gerência dos negócios públicos". (BONAVIDES, Paulo. Ciência política. 140 ed. São Paulo: Malheiros, 2007, p. 157). 
busca da efetividade27 dos direitos de cunho social, tolhendo o desenvolvimento de instituições sócio democráticas. ${ }^{28}$

Corrobora com a afirmação retro o pensamento de José Afonso da Silva

Hoje, o princípio não configura mais aquela rigidez de outrora. A amplidão das atividades do estado contemporâneo impôs nova visão da teoria da separação de poderes e novas formas de relacionamento entre os órgãos legislativo e executivo e destes com o judiciário, tanto que atualmente se prefere falar em colaboração de poderes, que é a característica do parlamentarismo, em que o governo depende da confiança do Parlamento (Câmara dos Deputados), enquanto, no presidencialismo, desenvolveram-se as técnicas $\mathrm{da}$ independência orgânica e harmonia dos poderes. ${ }^{29}$

A separação dos poderes é técnica em declínio, em face da necessidade de novos requisitos para o equilíbrio político e da acomodação de esquemas políticos que não mais se coadunam com o formalismo na proteção dos direitos individuais, conforme a finalidade do Estado Liberal. ${ }^{30}$

Atente para o fato de que a teoria da divisão dos poderes é uma ideia, e como tanto sua concretização varia de ordenamento jurídico para

27 Gustavo Binenbojm fala sobre o apogeu das agências reguladoras no EUA, em momento subsequente a grande depressão: "além disso, os reformadores acreditavam que o sistema de tripartição dos poderes e de freios e contrapesos gerava disputas políticas entre facções que impediam os servidores públicos de servir ao interesse público de médio e longo prazo". (BINENBOJM, Gustavo. Agências reguladoras independentes e democracia no Brasil. IN: BINENBOJM, Gustavo (coord). Agências reguladoras e democracia. Rio de Janeiro: Lumen Juris, 2006, p. 91-92).

\footnotetext{
28 "Desde porém que se desfez a ameaça de volver o estado ao absolutismo da realeza e a valoração política passou do plano individualista ao plano social, cessaram as razões de sustentar, em termos absolutos, um princípio que logicamente paralisava a ação do poder estatal e criara consideráveis contra-sensos na vida de instituições que se renovam e não podem conter-se, senão contrafeitas, nos estreitíssimos lindes de uma técnica já obsoleta e ultrapassada". (BONAVIDES, Paulo. Ciência política. ob. cit., p. 157). "Em geral, pode-se afirmar que o princípio constitucional da separação dos Poderes, consagrado como cláusula pétrea no art. 60,4으. III, da Carta de 1988, deve assumir uma 'noção menos mitificadora e mais pragmática', pois convive com outros princípios com os quais pode colidir". (KRELL, Andreas J. Leis de normas gerais, regulamentação do poder executivo e cooperação intergovernamental em tempos de reforma federativa. Belo Horizonte: Fórum, 2008, p. 71-72).

29 SILVA, José Afonso da. Curso de direito constitucional positivo. $22^{\circ}$ ed. São Paulo: Malheiros, 2003, p. 109.

30 "É necessário ter em mente que a teoria da tripartição de poderes nunca chegou a ser aplicada de modo homogêneo nem em termos radicais". (JUSTEN FILHO, Marçal. O direito das agências reguladoras independentes. São Paulo: Dialéctica, 2002, p. 344).
} 
ordenamento jurídico, variando sua estrutura em face do momento histórico, aferindo que não há uma separação de poderes, mas sim, várias separações de poderes.

Em verdade, retirando feição sacramental desse princípio em questão, sua essência material resume-se numa "divisão das atribuições do Estado entre órgãos distintos, ensejando uma salutar divisão de trabalho e um empecilho à historicamente perigosa concentração de poderes". ${ }^{31}$

Nesses termos, fica impossível concluir que os três órgãos-poderes só possam exercer uma das três funções e mais, de que todas as funções do Estado devam subsumir a apenas uma destas três funções estatais esculpidos na teoria da separação dos poderes. ${ }^{32}$

Paulo Bonavides, assim se posiciona:

O princípio perdeu pois autoridade, decaiu de vigor e prestígio. Vêmo-lo presente na doutrina e nas Constituições, mas amparada com raro proselitismo, constituindo um desses pontos mortos do pensamento político, incompatíveis com as formas mais adiantadas de progresso democrático contemporâneo, quando, erroneamente interpretado, conduz a uma separação extrema, rigorosa e absurda. ${ }^{33}$

Constata o início do processo de desvalor desse princípio quando houve a necessidade do Estado em intervir na economia e no meio social, no intuito de corrigir as contradições do capitalismo.

Essa nova realidade social e econômica, na qual exige a criação de novos direitos (sociais e metaindividuais), entram em choque com o modelo político do séc. XVIII, vindo a impedir a concretização desses novos direitos, o que vem por ensejar um processo adaptativo do princípio da separação dos poderes em face da nova conjuntura fática.

\footnotetext{
31 ARAGÃO, Alexandre Santos de. Legalidade e regulamentos no direito contemporâneo. Uma análise doutrinária e jurisprudencial. Revista de Direito Constitucional e Internacional. São Paulo: n. 41, p. 284-310, ed. RT, outubro-dezembro-2002, p. 286.

32 Cf. ARAGÃO, Alexandre Santos de. Legalidade e regulamentos no direito contemporâneo. Uma análise doutrinária e jurisprudencial. Revista de Direito Constitucional e Internacional. Ob. cit., p. 286.

33 BONAVIDES, Paulo. Ciência política. $14^{\circ}$ ed. São Paulo: Malheiros, 2007, p. 157-158.
} 
Veja que os objetivos dos Estados são constantemente revistos, reelaborados, harmonizados entre si, o que enseja projeções de modelos de ordenações e planejamentos referente as ações políticas internas e externas, o que permite constatar que as diretrizes estatais vão muito além da mera execução de leis pelo governo, extrapolando o esquema de legislação, jurisdição e execução. ${ }^{34}$

Salienta Paulo Bonavides:

Será em vão todo esforço que buscar outra diretriz para elucidar os rumos presentes do constitucionalismo moderno, respeitante ao sistema em que se apoia a técnica de distribuição de poderes.

No entanto, essa oscilação política para a igualdade, que em nosso século é sobretudo oscilação de cunho social e econômico, revela-se como antinomia perante a liberdade clássica, que o século XVIII conheceu. ${ }^{35}$

Complementa tal ilação de Paulo Bonavides, a afirmação de Eros Grau36: "A separação dos poderes constitui um dos mitos mais eficazes do Estado Liberal, coroado na afirmação, inscrita no art. 16 da Declaração dos Direitos do Homem ${ }^{37}$...".

De tal maneira, a vitória da teoria da tripartição dos poderes, sedutora, decorrente da opressão política do absolutismo, não vislumbrada pelos teóricos da época, visto que, a contradição da divisão de poder expunha a fragilidade o princípio básico da soberania, onde uma das duas características, prelecionadas por Jean-Jacques Rousseau, era a sua indivisibilidade.

${ }^{34}$ Cf. ARAGÃO, Alexandre Santos de. Legalidade e regulamentos no direito contemporâneo. Uma análise doutrinária e jurisprudencial. Revista de Direito Constitucional e Internacional. São Paulo: n. 41, p. 284-310, ed. RT, outubro-dezembro-2002, p. 287.

35 BONAVIDES, Paulo. Do Estado liberal ao Estado social. $5^{\circ}$ ed. Belo Horizonte: Del Rey, 1983, p. 65.

36 GRAU. Eros Roberto. O direito posto e o direito pressuposto. 60 ed. São Paulo: Malheiros, 2005, p. 225.

37 Art. 16. A sociedade em que não esteja assegurada a garantia dos direitos nem estabelecida a separação dos poderes não tem Constituição. (Declaração dos Direitos dos Homens e do Cidadão de 26 de setembro de 1789) 
Atente que apesar da sua importância como meio de quebrar as barreiras do antigo regime, a divisão dos poderes consubstanciou os ideais do liberalismo de limitação máxima dos fins do Estado. Fins estes alargados pelo Estado Social e posteriormente, em sua evolução, pelo Welfare State, onde se começou a teorizar sobre os meios de correção da fragilidade em que vivia a soberania.

Nos dias atuais se busca abandonar expressões como separação e divisão do poder, para fazer uso, a saber, distinção, coordenação e colaboração.

Há teóricos constitucionalistas que não utilizam mais a expressão poder e sim função. ${ }^{38}$ Sem dúvida denota maior adequação aos fins, atuais, do Estado, estendidas a um maior número de responsabilidades econômicas e sócias, o que vem por desconfigurar sua base formalista e meramente tutelar, convertendo em elementos de cunho material consubstanciando um novo conceito de Estado.

Ao examinarmos atentamente os mecanismos constitucionais atuais, sem dúvida, muitas técnicas foram utilizadas para atenuar as insofismáveis desmedidas da teoria da tripartição dos poderes.

Indubitavelmente o sistema de freios e contrapesos constitui uma dessas técnicas, o qual tem por fito proporcionar instrumentos para que os poderes possam realizar controles recíprocos no intuito de evitar abusos. ${ }^{39}$

Seria exemplo dessa técnica de equilíbrio os vetos e mensagens existentes na relação do executivo com o legislativo; hipóteses de iniciativa de lei exclusiva do Executivo; o instituto do indulto, do qual, faz uso o Executivo

\footnotetext{
38 "[...] hoje em dia poucos se mantêm apegados ao dogma da divisão dos poderes, e a nossa história constitucional nos dá um exemplo característico das modificações sofridas pela doutrina, desde a sua primeira formulação clássica até a Constituição Federal vigente, na qual a divisão de poderes soberanos não tem mais o valor de um princípio essencialmente destinado à garantia das liberdades individuais, mas antes um valor pragmático de uma distribuição de funções, de uma simples aplicação da lei da divisão do trabalho no setor das atividades políticas". ${ }^{38}$

39 "A teoria da separação dos poderes, entretanto, não resolve de forma absoluta - nem sequer poderia - o delicado problema do equilíbrio, entre os "poderes" do Estado. Deveras, como é sabido, cada Poder exerce sua função própria, não com exclusividade. Cada Estado, por intermédio de sua Constituição e de seu sistema de governo deve encontrar a solução que melhor implemente o princípio e a teoria dos checks and controls. Sabemos também, que a produção normativa, em sentido amplo, hoje é compartilhada. Não é só afeta ao Poder Legislativo. Já a Administração cabe ao Executivo apenas quando encarada em sentido estrito". (MAZZA, Alexandre. Agências reguladoras. São Paulo: Malheiros Editora, 2005, p. 53).
} 
interferindo nas medidas de cunho penal do Poder Judiciário; a nomeação de certos cargos públicos feitas pelo Executivo, a qual necessita da sabatina do Poder Legislativo; o Legislativo que em função de certos crimes perpetrado por certas autoridades faz-se de tribunal, entre outras situações.

Constata-se que com esse sistema muitas portas foram abertas nas relações entre os poderes, quebrando aquela ideia de atuação estanque de cada poder, como preconizado na realidade do Estado Liberal.

Georg Jellinek ${ }^{40}$, citado na obra de Paulo Bonavides, aponta que a teoria da tripartição dos poderes tinha cunho meramente político, sendo uma contradição frontal a unidade e indivisibilidade do poder estatal. ${ }^{41}$

Tal divisão do poder teve por consequência a fundação do Estado Constitucional e a organização do Estado Federal. Atente como prelecionada Heidelberg ${ }^{42}$ a confusão que se faz entre soberania e poder estatal, isso fruto de interpretações equivocadas da obra de John Locke e Montesquieu. ${ }^{43}$

No Estado Constitucional, vislumbra-se a corporificação da soberania como órgão de Estado. Na perspectiva moderna da organização federal do Estado não se confere soberania a determinado órgão, prevalecendo a unidade do poder estatal.

${ }^{40}$ Apud, BONAVIDES, Paulo. Do Estado liberal ao Estado social. $5^{\circ}$ ed. Belo Horizonte: Del Rey, 1983, p. 65.

41 "... a organização de Poderes do constitucionalismo clássico, fundada na supremacia da lei e do órgão legislativo, apresenta um defeito irremediável, qual seja, a ausência de um órgão de impulsionamento da ação estatal. Rompendo com o esquema constitucional consagrado, o Poder Executivo assumiu, em todos os países, essa função natural de liderança, tornando-se, de fato, o principal Poder." (Cf. COMPARATO, Fábio Konder. A organização da função planejadora. CAMARGO, Ricardo Antônio Lucas (coord). Desenvolvimento Econômico e Intervenção do Estado na Ordem Constitucional - Estudos Jurídicos em Homenagem ao Prof. Washington Peluso Albino de Souza. Porto Alegre: Sergio Antonio Fabris Editor, 1995, p. 81.

42 Apud, BONAVIDES, Paulo. Do Estado liberal ao Estado social. $5^{\circ}$ ed. Belo Horizonte: Del Rey, 1983, p. 65.

43 "... há de ser ressaltado que a chamada divisão de poderes não se confunde, sobretudo no Estado de Direito democrático, com uma divisão do poder do Estado. Uma fragmentação do poder estatal, ou seja, uma organização jurídica baseada em princípios diferenciados, afigura-se inimaginável. Já para Locke e Montesquieu não se cuidava de uma divisão do poder estatal, mas de uma distribuição do seu exercício entre diferentes órgãos, independentes entre si". (CF. KIMMINICH, Otto. Jurisdição constitucional e princípio da divisão de poderes. Material da $3^{a}$ aula da Disciplina Direito Constitucional: noções fundamentais, ministrada no Curso de Especialização Telepresencial e Virtual em Direito Constitucional - UNISUL-IDPREDE LFG, p. 07) 
George Jellinek ${ }^{44}$ ao analisar o Estado Jurídico afirma que a unidade do poder é preservada na obra de Jean-Jacques Rousseau, pois a soberania, que antes pertencia ao Rei, passou a se apoiar na vontade geral, ou seja, fora transferido ao povo, tendo assim o fito da democracia.

Conclui assim o filósofo genebrês ${ }^{45}$ que o constituinte francês na Declaração dos Direito dos Homens absteve-se em levar as últimas consequências, a divisão dos poderes, resolvendo instituir o Poder Legislativo como órgão capaz de concentrar todos os poderes.

De tal forma o princípio da soberania é preservado, tendo em seu cerne o povo, conferindo a divisão dos poderes uma importância secundária e relativa.

Portanto, temos assim, a unidade política do poder intacto, tendo por fonte primária o povo. Não se pode falar em divisão de poderes, pois esse não se subdivide, seja subjetivamente ou na atividade, o que se divide, é o objeto do poder, se muito, há divisão é de competência. ${ }^{46}$

Diversos autores aferem que a principal consequência da desmistificação inexpurgável do princípio da tripartição dos poderes é o surgimento de órgãos auxiliares aos ditos poderes supremos, onde muitos possuem previsão até mesmo constitucional. Avalia-se que a outorga de funções normativas a órgãos além da administração central, no Estado Moderno do séc. $X X$, tornou-se um fenômeno universal, onde sua prática vai avolumando-se cada vez mais. ${ }^{47}$

Conceber a divisão dos poderes num sistema ideal de distribuição de poderes entre entidades e órgãos, mascara o fato de que o mesmo é permeado por um valor de meios e não de dogma, o que, todavia, permite

\footnotetext{
44 Apud, BONAVIDES, Paulo. Do Estado liberal ao Estado social. $5^{\circ}$ ed. Belo Horizonte: Del Rey, 1983, p. 66.

45 Apud, BONAVIDES, Paulo. Do Estado liberal ao Estado social. $5^{\circ}$ ed. Belo Horizonte: Del Rey, 1983, p. 66.

46 Apud, BONAVIDES, Paulo. Do Estado liberal ao Estado social. $5^{\circ}$ ed. Belo Horizonte: Del Rey, 1983, p. 67.

47 Cf. ARAGÃO, Alexandre Santos de. Agências reguladoras e a evolução do direito administrativo econômico. $2^{\circ}$ ed. Rio de Janeiro: Forense, 2006, p. 375.
} 
a concepção de exceções ao princípio em questão. ${ }^{48}$ Ou seja, sempre que o interesse geral, a priori, justifique a necessidade de outorga de funções a órgãos auxiliares e independentes, em nada comprometerá esse princípio. ${ }^{49}$

Alexandre Aragão ${ }^{50}$ assim lapida:

(...) se relativizada a ideia "clássica" e absoluta de separação dos poderes, o amplo poder regulamentar dos órgãos e entidades da Administração Pública em nada contraria a divisão de funções estabelecida pelas constituições contemporâneas e os valores do Estado de Direito, que, afinal, constituem o principal parâmetro da admissibilidade não do exercício de distintas funções estatais pelo mesmo órgão-Poder... Em outras palavras, não serão as acumulações de poderes sempre constitucionais, mas, certamente o serão, se privilegiarem os valores do estado de Direito.

Concorda-se com Paulo Bonavides ${ }^{51}$ quando afirma que na conjectura atual, não se necessita mais lutar pela liberdade contra a ação do Estado, mas sim encontrar a liberdade no Estado, apresentando-se, de tal forma, obsoleta a teoria da divisão dos poderes, bem como a hipertrofia dos fins estatais, como já demonstra a história, isso nos levará a regimes totalitaristas.

48 "E certo também, corno mencionado, que tais funções não são, no Estado contemporâneo,
exercidas com exclusividade por cada um dos chamados "Poderes". Assim, apresentam-se
corno "exceções" ao princípio, exemplificativamente, no caso brasileiro: (i) o Legislativo julga
(em caso de impeachment, o Senado Federal exerce a função de processar e julgar o
Presidente da República em crimes de responsabilidade, bem corno Ministros de Estado e
comandantes das forças armadas em crimes de mesma natureza conexos com o do
Presidente, cfr. art. 52, I da Constituição); (ii) o Judiciário (corno todos os outros Poderes)
exerce funções administrativas (art. 96, I, da Constituição); (iii) e - o que é mais relevante
para este estudo - o Executivo legisla (através de Medida Provisória - MP, cfr. art. 62, da
Constituição, e regulamentos, art. 84, IV e VI, da Constituição)". (CYRINO, André Rodrigues.
O poder regulamentar autônomo do presidente da república. Belo Horizonte: Fórum, 2005, p. 36)

${ }^{49}$ Cf. ARAGÃO, Alexandre Santos de. Legalidade e regulamentos no direito contemporâneo. Uma análise doutrinária e jurisprudencial. Revista de Direito Constitucional e Internacional. São Paulo: n. 41, p. 284-310, ed. Revista dos Tribunais, outubrodezembro-2002, p. 288.

50 ARAGÃO, Alexandre Santos de. Legalidade e regulamentos no direito contemporâneo. Uma análise doutrinária e jurisprudencial. Revista de Direito Constitucional e Internacional. Ob. cit., p. 288.

51 BONAVIDES, Paulo. Do Estado liberal ao Estado social. $5^{\circ}$ ed. Belo Horizonte: Del Rey, 1983, p. 74. 
O autor, retro, nos brinda com a sua opinião de como obter a liberdade no Estado, tendo por base um sistema de governo parlamentarista:

Em nossa humilde opinião, o sistema parlamentarista contemporâneo, que remove a pretensa incomunicabilidade dos poderes, que impõe a supremacia do legislativo e constitui ordem qualitativamente superior de organização política do Estado, é o sistema que mais se compadece com a moderna proteção constitucional da liberdade, proteção que deixa de ser preponderantemente jurídica (democracia presidencialista) para se tomar política, dissolvendo, contudo, a antinomia Estado-indivíduo.

O presidencialismo, mais afeiçoado ao liberalismo e amparado em técnica rígida de separação de poderes, afigura-se-nos método que retarda dificulta aquela passagem do humano ao social, que já se opera irreversivelmente no Estado contemporâneo...

Desconhecer essa realidade e ater-se a formas obsoletas e ineptas, amor da tradição, como no caso da clássica teoria da separação de poderes, significa cerrar os olhos às novas perspectivas que o constitucionalismo deste século, com a propagação do sistema parlamentarista (no aspecto vertente igual a vinculação de poderes e hegemonia do legislativo) oferece aos povos empenhados em transpor democraticamente a crise do Estado moderno, transição do individualismo ao socialismo. ${ }^{52}$ (Grifos nossos)

Esse excerto da obra de Paulo Bonavides demonstra como a teoria da tripartição dos poderes se configura de forma diversa, em face da organização política. Em decorrência da apropriação pela função administrativa em reputar as escolhas do que seria o interesse público, passou ao Poder Executivo a competência de eleger as políticas e os fins concretos. $^{53}$

Tendo em vista essa apropriação é que Paulo Bonavides afirma que o sistema Parlamentarista é o mais adequado, pois a atividade do chefe de governo encontra-se constantemente fiscalizado pelo Poder Legislativo,

\footnotetext{
52 BONAVIDES, Paulo. Do Estado liberal ao Estado social. $5^{\circ}$ ed. Belo Horizonte: Del Rey, 1983, p. 75.

53 Cf. JUSTEN FILHO, Marçal. O direito das agências reguladoras independentes. São Paulo: Dialéctica, 2002, p. 351.
} 
onde aspirações incompatíveis com o interesse na Nação vêm gerar a destituição do Primeiro Ministro. Já no sistema Presidencialista o processo de destituição do presidente é extremamente complexo e burocrático, o que dá margem a uma alta autonomia ao Presidente em relação as escolhas para Nação, não havendo instrumentos para o devido controle, o que gera a personificação do poder na figura do mesmo. ${ }^{54}$

\section{ESCOPO HISTÓRICO DAS AGÊNCIAS REGULADORAS}

A tendência para uma regulação de um poder sobre outro começou a se difundir desde o século XVII, como já previa "O regime da common law inglês comportava instrumentos para fiscalização e repressão de atos indevidos praticados tanto por particulares como por servidores da Coroa", como relata Justin Filho. ${ }^{55}$

A agência reguladora tem como origem a Inglaterra da Primeira Revolução Industrial do século XIX, criada pelo Parlamento inglês e tinha como finalidade concretizar medidas previstas em lei ou decidir eventuais controvérsias resultantes dessa lei, mas tem 0 seu completo desenvolvimento nos EUA. Traz consigo resquícios do regime britânico, quanto aos aspectos do direito administrativo, porque os EUA foram colônia inglesa e como tal, muito herdou.

Os fins são o escopo da delegação de poderes para as agências reguladoras. O new Deal e a "primeira onda" ${ }^{56}$ das agências provocaram uma alteração da common law, nos EUA, dentro do contexto da crise de 1929.

Verificou-se que a common law era omissa no que se referia aos direitos sociais e uma pluralidade de interesses privados (identificados como os

${ }^{54}$ Cf. JUSTEN FILHO, Marçal. O direito das agências reguladoras independentes. Ob. cit., p. 352.

55 É importante acrescentarmos que "a experiência acerca da regulação foi intensamente desenvolvida após a independência dos EUA, mas isso se deu a partir de uma tradição largamente conhecida no período anterior, durante a dominação inglesa" (JUSTIN FILHO, Marçal. $O$ direito das agências reguladoras independentes. São Paulo: Dialética, 2002, p. 70).

56 JUSTIN FILHO, Marçal. O direito das agências reguladoras independentes. São Paulo: Dialética, 2002, p.78. 
direitos difusos e coletivos). Na "segunda onda"57 nos anos de 60 e 70, reconheceu-se que o mercado era insuficiente para produzir aqueles resultados tidos como desejados e necessários à realização axiológica. A intervenção veio, desse modo, a eliminar os efeitos indesejados do livre jogo das forças de mercado. A partir de então, surgirão inúmeras agências, para as mais variadas atividades, de acordo com o aparecimento das necessidades.

Lehfeld $^{58}$ relata o ensinamento de Heich, que assevera que o Estado brasileiro passa por três diferentes fases no decorrer do século XX.

A primeira denominada de pré-modernidade caracteriza-se por ter um Estado com reduzida funcionalidade, pautado na segurança, nos serviços públicos essenciais e na prestação jurisdicional.

$\mathrm{Na}$ segunda, modernidade, o Estado avoca determinadas funções econômicas, incorporando o fomento do desenvolvimento econômico, atividades sociais de cunho distributivo. Essa fase promove o fortalecimento dos direitos sociais, no que se refere a emprego, condições mínimas de trabalho, e suas garantias trabalhistas.

Na última fase, pós-modernidade ou contemporânea, verifica-se a ineficiência generalizada do Estado, marcada pela obsolescência industrial, morosidade nas respostas às necessidades sociais, desperdício de recursos públicos, excesso de burocracia e corrupção na coisa pública.

É neste contexto que surgem, no Brasil, as agências reguladoras, a partir da década de 90, iniciando-se com a privatização de áreas estratégicas, de monopólio do Estado, bem colocado por José Bonifácio de Souza Filho:

A evolução mundial ocorrido principalmente nos anos 1980 e 90 levou países, a começar pela Inglaterra e os estados Unidos, a delegar à iniciativa privada as tarefas relativas aos serviços públicos... O Estado prestador de serviços públicos deve ser substituído pelo Estado

\footnotetext{
57 JUSTIN FILHO, Marçal. O direito das agências reguladoras independentes. São Paulo: Dialética, 2002, p. 79.

58 De acordo com Lehfeld, há nesse período diversas rupturas com estruturas jurídicas e políticas oriundas do Estado liberal e do Welfare State, devido a intensificação do processo de globalização, da revolução das comunicações e da tecnologia, não apenas no Brasil, mas em todo o mundo (LEHFELD, Lucas de Souza, Controle das agências reguladoras. São Paulo: Atlas, 2008, p. 226).
} 
regulador. A iniciativa privada deve assumir o papel do estado prestador de serviços públicos, mas deve haver uma regulação eficiente por parte do Estado. ${ }^{59}$

A grande problemática se estabelece quando se circunscreve o âmbito de atuação das agências reguladoras.

\section{AS AGÊNCIAS REgULADORAS E SUA ADEQUAÇÃO AO PRINCÍPIO DA SEPARAÇÃO DOS PODERES}

Celso Antônio Bandeira de Melo defende que "se interdita ao executivo expedir decretos e regulamentos senão para executar fielmente a lei"60 e dentro do contexto da Constituição de 88 afirma que "de nada adiantaria os arts. 50, II, e 84, III, se, ulteriormente, o legislador pudesse entregar de mão beijada, a esfera da liberdade e da propriedade dos administrados para ser disciplinada por via de regulamento". ${ }^{61}$

Sem menosprezar a defesa do eminente jurista, o presente trabalho defende posição contrária à sua, pois conforme Sundfeld, "No Brasil o debate é, em essência, o mesmo, embora se deva observar que para muitas medidas a Carta de 1988 estabeleceu uma reserva legal, que há de ser observada". ${ }^{62}$

Moncada observa uma questão intrigante, no que diz respeito à lei em si, elaborada pelo legislativo, em sua análise, e afirma que há razões para desconfiarmos da lei do ponto de vista do Direito:

59 CASTRO, Carlos Roberto Siqueira. Função normativa regulatória e o novo princípio da legalidade. IN: ARAGÃO, Alexandre Santos de (org). O poder normativo das agências reguladoras. Rio de Janeiro: Forense, 2006, p. 62.

60 MELLO, Celso Antônio Bandeira de. "Poder" regulamentar ante o princípio da legalidade. Revista Trimestral de Direito Público. São Paulo: n. 72-78, Malheiros, 1993, p. 72.

61 O autor é peremptório e em outros trabalhos já defendia que "A legalidade na administração não se resume à ausência de oposição à lei, mas pressupões autorização dela, como condição de sua ação". MELLO, Celso Antônio Bandeira de. "Poder" regulamentar ante o princípio da legalidade. Revista Trimestral de Direito Público. São Paulo: n. 72-78, Malheiros, 1993, p. 76.

62 SUNDFELD, Carlos Ari (Coordenador). Direito administrativo econômico. São Paulo: Malheiros, 2006, p.28. 
É que a qualidade da lei é cada vez menor. Preocupada com a eficiência das medidas que corporiza, inserida em estratégias políticas partidárias e cada vez mais elaborada fora do quadro do contraditório parlamentar, à mercê, portanto, dos grupos de interesses e dos arrivistas, a lei é amiúde um texto que deixa a desejar do ponto de vista da sua qualidade normativa. ${ }^{63}$

Ainda, o mesmo autor afirma que "Tudo se conjuga hoje, efectivamente, para que a lei parlamentar deixe de ser o centro da ordem jurídica". ${ }^{64}$ É a transferência para o Poder Executivo de capacidades normativas, sofrendo estas apenas intervenções parlamentares no que se refere a acertos $e$ acrescentamentos a propostas de lei de autoria estranha. E acrescenta que isto se refere a um "pluralismo legislativo, característico do actual estado de coisas, não beneficiou, como não podia deixar de ser, o parlamento". ${ }^{65}$

Após essas colocações do posicionamento de Luís Cabral de Moncada, insere-se uma problemática acerca das agências reguladoras como um ente que, a partir de suas atividades, é, por alguns, tida como entidades que ferem a tripartição dos poderes, e que julgam que estas seriam um quarto poder, ferindo assim os preceitos constitucionais.

Lehfeld sai em defesa das agências reguladoras e constata em sua análise que "o fundamento das competências legislativa e jurisdicional dessas entidades reguladoras somente se concebe a partir de uma evolução interpretativa da Teoria da Separação dos Poderes". ${ }^{66}$ E acrescenta corroborando com a ideia de que as complexidades sociais e o incremento das atividades do Estado em prol do bem-estar, faz com que

[...] a concepção clássica consagrada na obra de Montesquieu não mais se mostra suficiente para compreender sua dimensão neoliberal, especialmente

\footnotetext{
63 MONCADA, Luís S. Cabral de. Ensaio sobre a lei. Coimbra: Coimbra Editora, 2002, p. 06.

64 MONCADA, Luís S. Cabral de. Ensaio sobre a lei. Coimbra: Coimbra Editora, 2002, p. 95.

65 MONCADA, Luís S. Cabral de. Ensaio sobre a lei. Coimbra: Coimbra Editora, 2002, p. 96.

66 LEHFELD, Lucas de Souza, Controle das agências reguladoras. São Paulo: Atlas, 2008, p. 164.
} 
no que diz respeito à sua presença reguladora em setores privados por meio de suas agências. ${ }^{67}$

A tentativa de se manter uma inflexível teoria da tripartição dos poderes, assim como foi pensada em Aristóteles, ${ }^{68}$ revisada por Locke $^{69}$ e desenvolvida por Montesquieu, ${ }^{70}$ nos moldes atuais, não atende as necessidades da sociedade em seus aspectos político-econômicos, o que se reflete no olhar perspicaz de Alexandre Aragão

Se o princípio da separação dos poderes sempre foi um preceito meramente ideal, nunca aplicado integralmente na letra e muito menos na prática das constituições, a democratização do Estado, com a sua crescente participação nas relações sociais e econômicas, acarretou uma considerável mudança do polo do poder do legislativo para o "executivo". ${ }^{71}$

Na mesma linha encontra a percepção de Gomes Canotilho, quando assevera no que diz respeito à instrumentalidade e flexibilidade no sistema jurídico do Estado Democrático de Direito, o qual configura-se com um sistema aberto com uma estrutura dialógica que permite a construção e reconstrução da normatividade constitucional em face da realidade inspirado por valores de conceitos indeterminados como a "justiça". ${ }^{72}$

Prosseguindo ainda com Aragão, que ilustra seu posicionamento com relação a separação dos poderes

${ }^{67}$ LEHFELD, Lucas de Souza, Controle das agências reguladoras. São Paulo: Atlas, 2008, p. 165 .

68 GRAU, Eros Roberto. O direito posto e o direito pressuposto. São Paulo: Malheiros, 2005, p.226.

69 GRAU, Eros Roberto. O direito posto e o direito pressuposto. São Paulo: Malheiros, 2005, p.227.

70 GRAU, Eros Roberto. O direito posto e o direito pressuposto. São Paulo: Malheiros, 2005, p. 229.

71 ARAGÃO, Alexandre Santos de. Agências reguladoras e a evolução do direito administrativo econômico. Rio de Janeiro: Forense, 2006, ps. 64-65.

72 CANOTILHO, José Joaquim Gomes. Direito Constitucional. 70 ed. Coimbra: Almedina, 2000 , p. 1123. 
A separação dos poderes foi concebida num momento histórico em que se pretendia limitar o poder do Estado e reduzir ao mínimo a sua atuação. Mas a evolução da sociedade criou exigências novas, que atingiram profundamente o Estado. Este passou a ser cada vez mais solicitado a agir, ampliando sua esfera de ação e intensificando a sua participação nas áreas tradicionais. Tudo isso impôs a necessidade com os modelos da separação de poderes. O legislativo não tem condição para fixar regras sem ter conhecimento do que já foi ou está sendo feito pelo executivo e sem saber de que meios este dispõe para atuar. O executivo, por seu lado, não pode ficar à mercê de um lento processo de elaboração legislativa, nem sempre adequadamente concluído, para só então responder às exigências sociais, muitas vezes graves e urgentes. ${ }^{73}$

Incute a esse respeito a abordagem sobre a leitura da norma envolta do contexto ao qual se insere num determinado momento. Assim, GarciaPelayo afirma que "cualquier norma está inserta y condicionada por una situación histórica, que no sólo da lugar a la creación de nuevas normas, sino que también otorga nuevo sentido a las existentes, penetrando de este modo en su contenido". ${ }^{74}$

Com relação aos aspectos jurisdicionais, a análise é feita na possibilidade das agências reguladoras apaziguarem conflitos. Exalta-se a reflexão encartada em Conrado Mendes quando acolhe que

Não é falsa a afirmação da existência de um poder de dirimir conflitos no universo de competências das agências. Isto, porém, de maneira alguma afasta o princípio básico determinante em nosso sistema político democrático, albergado pelo art. $5^{\circ}, \mathrm{XXXV}^{75}$

Sundfeld apregoa que a repulsão se dá pelo fato de ser difícil para nós compreendermos e aceitarmos que o Judiciário não seja o único órgão para

73 ARAGÃO, Alexandre Santos de. Agências reguladoras e a evolução do direito administrativo econômico. Rio de Janeiro: Forense, 2006, p. 102.

74 GARCIA-PELAYO, Manuel. Derecho Constitucional comparado. Madri: Revista de Ocidente, S.A., 1957, p. 64.

75 MENDES, Conrado Hubner. Reforma do Estado e agências reguladoras: Estabelecendo os parâmetros de discussão. IN: SUNDFELD, Carlos Ari (coordenador), Direito Administrativo Econômico. São Paulo: Malheiros, 2006, p. 131 
dirimir e solucionar os conflitos, e reconhece que a sua estrutura esculpida no século passado o inviabiliza para dirimir todas as demandas da sociedade moderna em mutação em profícua construção de novos valores. ${ }^{76}$

As agências reguladoras atuam nos aspectos normativos e jurisdicionais, mas dentro de um certo limite, naquilo que é intangível ao legislativo e ao judiciário, por estes não possuírem conhecimentos específicos, de modo que promovem uma solução, ao caso concreto, de modo eficiente e célere.

A discussão acerca do tema é há muito tempo já debatida, nos aspectos que envolvem a fidelidade a tripartição dos poderes, e da mesma forma, já se defendia que essa teoria não é absoluta, como explicita Krell:

Também entre os constitucionalistas da República de Weimar era forte a ideia de que a conquista da soberania popular no novo regime democrático era inconciliável com a vetusta teoria da divisão dos Poderes e teria levado a um "monismo parlamentar unificador de Poderes". ${ }^{77}$

E acrescenta:

Já nos anos 50 do século passado, Loewenstein afirmava que "nada mostra com mais clareza a superação da tradicional tripartite 'separação dos poderes' do que a posição do governo no processo legislativo" ao qual o Executivo estaria "ligado de forma inseparável", sendo "quase obrigado a assumir a liderança na tomada de decisão política" e de "aceitar a responsabilidade pela execução das decisões tomadas, a qual, via de regra, também veste a roupagem da legislação". ${ }^{78}$

O autor tem o cuidado para expurgar a velha concepção com o escopo de se manter o mais puro atendimento ao princípio da tripartição dos poderes a

76 Cf. SUNDFELD, Carlos Ari (Coordenador). Direito administrativo econômico. São Paulo: Malheiros, 2006, p. 31.

77 KRELL, Andreas J. Leis de normas gerais, regulamentação do Poder Executivo e cooperação intergovernamental em tempos de Reforma Federativa. Belo Horizonte: Fórum, 2008, p. 73.

78 KRELL, Andreas J. Leis de normas gerais, regulamentação do Poder Executivo e cooperação intergovernamental em tempos de Reforma Federativa. Belo Horizonte: Fórum, 2008, p. 72. 
qualquer custo, o que é inviável em qualquer tempo, e assevera que perdurando uma visão clássica, na qual a supremacia do Legislativo tornase um verdadeiro dogma, rechaçando o crescimento da legitimidade do Poder Executivo, o que compromete o sistema de "pesos e contrapesos" põem-se em risco as liberdades civis em face de um administrador público usurpador. ${ }^{79}$

O argumento usado por Eros grau, deduzido do pensamento de Montesquieu, tange-se na necessidade de distinguir entre poderes e funções, de tal sorte que o princípio da tripartição dos poderes logre seu êxito, tem que o Poder Executivo tem que exercer duas funções além das parcelas executivas, adentrando na legislativa. ${ }^{80}$

\section{CONSIDERAÇÕES FINAIS}

No dinamismo social que se sucede, em volta da globalização, do desenvolvimento tecnológico, bem como, o surgimento e desenvolvimento de novos direitos, far-se-á necessário a reestruturação estatal para que possa gerenciar com eficácia essa mutação, cada vez mais veloz, do corpo social.

Para tanto, a visão estanque da teoria da tripartição dos poderes e o culto a figura da lei, que no Estado Liberal proporcionou a quebra das amarras do absolutismo e a promoção do individualismo, tendo por fito os ideais capitalistas e o apogeu da classe burguesa, não se faz mais úteis, tornando, na verdade um obste a atuação do Estado em efetivar os novos anseios da sociedade de massas.

Tem-se a necessidade, em virtude do acima esposado, do atuar estatal de forma mais célere, mais presente, e que consiga, se adaptar, em tempo hábil, às mudanças de "tendências", o qual, torna-se perfeitamente viável, quando se depende exclusivamente do Poder Legislativo como criadora de

\footnotetext{
${ }^{79}$ Cf. KRELL, Andreas J. Leis de normas gerais, regulamentação do Poder Executivo e cooperação intergovernamental em tempos de Reforma Federativa. Belo Horizonte: Fórum, 2008, p. 72.

${ }^{80}$ Cf. GRAU, Eros Roberto. O direito posto e o direito pressuposto. São Paulo: Malheiros, 2005, p. 233.
} 
normas, determinando o atuar dos demais poderes, principalmente do Poder Executivo.

De tal sorte, a técnica da tripartição dos poderes como concebido por Montesquieu, afigura forma de fragilizar o Estado, na medida em que, quebra a unidade do poder, pois despreza a característica fundamental da soberania, a sua indivisibilidade.

Como prelecionou Bonavides, a teoria da divisão dos poderes foi criada para conter a intervenção do Estado nas relações privadas, almejando ofertar a liberdade contra as opressões públicas. Entretanto, com o surgimento dos direitos sociais e metaindividuais, a busca da liberdade em face da ação do Estado, não é mais necessária, devendo-se ainda, encontrar a liberdade no atuar estatal.

Assim sendo, no intuito de permitir esse atuar estatal tem que se admitir o exercício do poder regulamentar pelo Executivo, sob o perigo do comprometimento da existência do Estado como conhecemos, pois, se ele não consegue suprir os fins para qual foi criado, deixa de haver a razão da sua existência.

Fica cristalino, em face do contexto mundial, principalmente do fim da década de 70 para cá, que com a realidade derivada da economia globalizada a manutenção da obediência a divisão dos poderes como concebido numa interpretação literal e liberal torna-se impossível, inviável e impraticável.

Com fito de executar as diversas funções estatais e concretizar os novos fins agregados as atribuições do Estado, a figura de órgãos auxiliares aos três poderes é constante e necessária, o que ensejou o aparecimento das chamadas agências reguladoras.

É clarividente que as funções atribuídas as agências reguladoras, em nada compromete a teoria da tripartição dos poderes, como deduz, a priori, muitos. Pelo contrário sua legitimidade e vitalidade insurgem exatamente do equilíbrio entre os influxos - pesos e contrapesos - exercidos pelo Poder Executivo, Judiciário e Legislativo em suas interações mútuas. 
Não só a teoria da divisão dos poderes precisa de uma nova interpretação, não podendo ser adotada de forma absoluta, bem como, também, em decorrência desta, necessita ser flexibilizado a visão formalista e liberal do princípio da legalidade.

Em um aspecto macro, abraçar o poder regulamentar, como manifestação da função normativa inerente de um poder uno e indivisível, mitigando a técnica da tripartição dos poderes, possibilita que o Estado seja um "animal, que pode adaptar-se ao meio ambiente", fazendo luzir a efetivação dos direitos fundamentais.

\section{REFERÊNCIAS DAS FONTES CITADAS}

ARAGÃO, Alexandre Santos de. Agências reguladoras e a evolução do Direito Administrativo. Rio de Janeiro: Forense, 2006. - Legalidade e regulamentos no direito contemporâneo. Uma análise doutrinária e jurisprudencial. Revista de Direito Constitucional e Internacional. São Paulo: n. 41, p. 284-310, ed. RT, outubro-dezembro-2002.

ARISTÓTEleS. Política. Tradução de Pedro Constantin. $5^{\circ}$ ed. São Paulo: Martin Claret, 2008.

BINENBOJM, Gustavo. Agências reguladoras independentes e democracia no Brasil. IN: BINENBOJM, Gustavo (coord). Agências reguladoras e democracia. Rio de Janeiro: Lúmen Juris, 2006

BONAVIDES, Paulo. Do Estado liberal ao Estado social. $5^{0}$ ed. Belo Horizonte: Del Rey, 1983

. Ciência política. $14^{\circ}$ ed. São Paulo: Malheiros, 2007.

. Teoria do Estado. 60 ed. São Paulo: Malheiros, 2007.

BOBBIO, Norberto. Direito e Estado no pensamento de Emanuel Kant. São Paulo: Mandarim, 2000. 
CASTRO, Carlos Roberto Siqueira. Função normativa regulatória e o novo princípio da legalidade. IN: ARAGÃO, Alexandre Santos de (org). O poder normativo das agências reguladoras. Rio de Janeiro: Forense, 2006.

CYRINO, André Rodrigues. 0 poder regulamentar autônomo do presidente da república. Belo Horizonte: Fórum, 2005.

COMPARATO, Fábio Konder. A organização da função planejadora. CAMARGO, Ricardo Antônio Lucas (coord). Desenvolvimento Econômico e Intervenção do Estado na Ordem Constitucional - Estudos Jurídicos em Homenagem ao Prof. Washington Peluso Albino de Souza. Porto Alegre: Sergio Antonio Fabris Editor, 1995.

COSTODIO FILHO, Ubirajara. A Emenda Constitucional 19/98 e o Princípio da Eficiência na Administração Pública. In: Cadernos de Direito Constitucional e Ciência Política, São Paulo: Revista dos Tribunais, n. 27, p. 210-217, abr./jul. 1999.

DALLARI, Dalmo, de Abreu. Elementos de teoria geral do Estado. São Paulo: Saraiva, 2011.

GARCIA-PELAYO, Manuel. Derecho constitucional comparado. $4^{\circ} \mathrm{ed}$. Madri: Revista de Ocidente, S.A., 1957.

GRAU, Eros Roberto. O direito posto e o direito pressuposto. São Paulo: Malheiros, 2005.

JUSTIN FILHO, Marçal. 0 direito das agências reguladoras independentes. São Paulo: Dialética, 2002.

KIMMINICH, Otto. Jurisdição constitucional e princípio da divisão de poderes. Material da $3^{a}$ aula da Disciplina Direito Constitucional: noções fundamentais, ministrada no Curso de Especialização Telepresencial e Virtual em Direito Constitucional - UNISUL-IDP-REDE LFG.

KRELL, Andreas J. Leis de normas gerais, regulamentação do Poder Executivo e cooperação intergovernamental em tempos de Reforma Federativa. Belo Horizonte: Fórum, 2008.

LEHFELD, Lucas de Souza. Controle das agências reguladoras. São Paulo: Atlas, 2008. 
NELSON, Rocco Antonio Rangel Rosso. ROCHA, Joyce Michelle de Melo. Do princípio da tripartição dos poderes: um estudo dogmático em relação as agências reguladoras. Revista Eletrônica Direito e Política, Programa de Pós-Graduação Stricto Sensu em Ciência Jurídica da UNIVALI, Itajaí, v.11, n.1, 10 quadrimestre de 2016. Disponível em: www.univali.br/direitoepolitica - ISSN 1980-7791.

MAZZA, Alexandre. Agências reguladoras. São Paulo: Malheiros, 2005.

MELLO, Celso Antônio Bandeira de. "Poder" regulamentar ante o princípio da legalidade. Revista Trimestral de Direito Público. São Paulo: n. 72-78, Malheiros, 1993.

MENDES, Conrado Hubner. Reforma do Estado e agências reguladoras: Estabelecendo os parâmetros de discussão. IN: SUNDFELD, Carlos Ari (coordenador), Direito Administrativo Econômico. São Paulo: Malheiros, 2006.

MONCADA, Luís S. Cabral de. Ensaio sobre a lei. Coimbra: Coimbra Editora, 2002.

MONTESQUIEU, Charles Louis de Secondat. O espírito das leis. Tradução de Antonio Lázaro de Almeida Prado. IN: Coleção "Os pensadores". São Paulo: Nova Cultural, 1996.

REALE, Miguel. Teoria geral do direito e do Estado. $5^{\circ}$ ed. São Paulo: Saraiva, 2005,

SALDANHA, Nelson. Formação da teoria constitucional. Rio de Janeiro: Renovar, 2000.

SILVA, José Afonso da. Curso de direito constitucional positivo. $22^{\circ}$ ed. São Paulo: Malheiros, 2003

SUNDFELD, Carlos Ari (Coordenador). Direito administrativo econômico. São Paulo: Malheiros, 2006.

Submetido em: Março de 2015.

Aprovado em: Março de 2015. 